\title{
Lead shielding efficiency from the gamma background measurements in the salt cavern of the Polkowice-Sieroszowice copper mine
}

\author{
Kinga Polaczek-Grelik ${ }^{1}$ Jan Kisiel ${ }^{1} \cdot$ Agata Walencik-Lata $^{1} \cdot$ Jerzy W. Mietelski $^{2}$ • \\ Paweł Janowski $^{2,3}$ - Małgorzata Harańczyk ${ }^{2}$. Jan Jurkowski ${ }^{2}$ - Agnieszka Zalewska ${ }^{2}$. \\ Jan Kobziński ${ }^{4} \cdot$ Paweł Markowski $^{4} \cdot$ Andrzej Sadowski $^{4}$
}

Received: 30 May 2015/Published online: 27 October 2015

(c) The Author(s) 2015. This article is published with open access at Springerlink.com

\begin{abstract}
The studies of lead shielding efficiency from the gamma background measurements were performed in the salt cavern of the copper mine - a site considered for an underground laboratory. Within the energy range of $50-2700 \mathrm{keV}$, the measured gamma-ray count rates normalized to the mass of the high-purity detectors germanium crystal are 5.93 and $6.32 \mathrm{~s}^{-1} \mathrm{~kg}^{-1}$ for the used low-background and portable spectrometers, respectively. The gamma-ray flux of $0.124(2) \mathrm{cm}^{-2} \mathrm{~s}^{-1}$ connected with the natural radioisotopes was observed by the portable HPGe, including 0.026 (1) $\mathrm{cm}^{-2} \mathrm{~s}^{-1}$ contribution of radon decay products, whereas the photon flux at the spectrum continuum was $0.18(5) \mathrm{cm}^{-2} \mathrm{~s}^{-1}$.
\end{abstract}

Keywords Gamma-ray spectrometry · Gamma background · Underground laboratory · Natural radioactivity - Lead shielding efficiency

\section{Introduction}

The measurements of very rare events, such as neutrinoless double beta decay, dark matter or nucleon decay searches, require extremely low background. Therefore, they are

Kinga Polaczek-Grelik

kinga.polaczek-grelik@us.edu.pl

1 Institute of Physics, University of Silesia, Uniwersytecka 4, 40-007 Katowice, Poland

2 IFJ PAN, Radzikowskiego 152, 31-342 Kraków, Poland

3 AGH University of Science and Technology, Mickiewicza 30, 30-059 Kraków, Poland

4 Polkowice-Sieroszowice Mine, Division of KGHM Polska Miedź S.A., Kaźmierzów, Poland performed in the underground physics laboratories, where the rock overburden reduces substantially cosmic radiation $[1,2]$. For instance, the muon flux is reduced by about 6 orders of magnitude at the depth of 2700 m.w.e [3]. However, the neutrons originating from $(\alpha, n)$ and the spontaneous fission reactions of $U$ and Th rock contamination together with neutrons from residual cosmic-ray muon interactions are the source of a rather complicated and unavoidable background [4]. The neutrons produce some effects in gamma-ray spectra, although they are detectable only when the main sources of gamma-ray background are reduced, resulting in the low continuous component of gamma-ray background spectrum.

The origin of gamma-ray background spectrum is complex. In the case of the studied conditions one can distinguish among several sources of gamma-ray emitters. The first one is due the gamma emitters from the salt. The second one is connected with radon daughters present in the air inside the cavern. The third one is due to the radionuclides present inside the detector crystal, cryostat, preamplifiers etc. The use of any kind of external detector's shielding reduces the first two components (coming from the outside of the spectrometer system), whereas the third one remains. Moreover, the shield introduces the fourth component to the background signal-the background caused by radionuclides inherent to the shield itself.

The aim of the study was to get the first empiric estimation of achievable gamma-ray background for our newly constructed low-background gamma spectrometer after its localization within the lead shield inside the P1 cavern in the Polkowice-Sieroszowice mine, KGHM Polska Miedź S.A. Holding. A similar estimation can be obtained in the course of Monte Carlo simulations; however, one has to make assumptions about the details of the geological surrounding of the cavern. The present estimation will be used 
to verify such simulations, which are planned for the future.

In this paper the results of in situ gamma background measurements performed in the P1 salt cavern in the Polkowice-Sieroszowice copper mine are presented. Two detectors were used: unshielded low-background HPGe (high purity germanium) detector recently constructed at the IFJ PAN, Kraków, Poland, and portable coaxial HPGe detector with reverse cathode (REGe), Canberra Industries Inc. Within the limitations of our experiment it was possible to take underground spectra only with light $(2.5 \mathrm{~cm}$ thick) not complete lead shield (collimator) for the portable detector. Finally, the estimation of the predicted count rates expected for some gamma-ray lines for our low-background detector shielded by $10 \mathrm{~cm}$ of lead are presented. Using two spectrometers with comparable detector parameters (mass, efficiency, housing, see: Experimental apparatus section) but different cryostat geometry (vertical dipstick vs. horizontal) and cryostat radioisotopic purity it was possible to better characterize the contribution of particular components of gamma radiation background.

The P1 cavern is located $930 \mathrm{~m}$ below the surface (2200 m.w.e.), in the salt deposit, which is about $70 \mathrm{~m}$ thick and surrounded by anhydrite layers. The P1 cavern is $100 \mathrm{~m}$ long, $20 \mathrm{~m}$ wide and $15 \mathrm{~m}$ high. The salt layer is considered as a possible location of an underground physics laboratory, the SUNLAB project. A more detailed description of the Polkowice-Sieroszowice mine can be found in [5]. The results of the measurements of natural radioactivity (the radioactive isotopes concentration, radon concentration and dose) performed in 2005 in the P1 salt cavern are presented in [6].

\section{Experimental apparatus}

Two coaxial semiconductor spectrometers were used: a low-background high-purity germanium (HPGe) detector and a commercially available portable in situ HPGe spectrometer. Additionally, the radon concentration was determined during the gamma radiation spectrum collection. This measurement was carried out about $50 \mathrm{~cm}$ above the salt ground for $30 \mathrm{~h}$ with the use of a portable detector Radon Alpha Detector (RAD- $7^{\mathrm{TM}}$, Durridge, USA), which is an active monitoring system based on passivated ionimplanted silicon detector (PIPS).

\section{Low-background laboratory spectrometer}

The n-type HPGe detector manufactured at IFJ PAN from Umicore germanium monocrystal (about $600 \mathrm{~g}$, $56 \mathrm{~mm}$ diameter, $53 \mathrm{~mm}$ height, $25 \%$ relative efficiency, $2.1 \mathrm{keV}$
FWHM at $1.33 \mathrm{MeV}{ }^{60} \mathrm{Co}$ line) was placed into a low background vertical (dipstick) cryostat produced by Baltic Scientific Instruments (Riga, Latvia). The total uranium and thorium concentration in the copper elements of cryostat (e.g. cold finger) is below $0.1 \mathrm{ppb}$, whereas in the aluminium alloys of the detector holder or endcap it is below $1 \mathrm{ppb}$. The cold finger and preamplifier housings are made of stainless steel. The endcap ( $83 \mathrm{~mm}$ in diameter) is equipped with a carbon fibre composite window $0.8 \mathrm{~mm}$ thick and $50 \mathrm{~mm}$ in diameter. The preamplifier is located more than $10 \mathrm{~cm}$ from the bottom of the endcap. The spectrometer operates with standard Canberra NIM modules: HV supply and amplifier, and Polish MCA Tukan $8 \mathrm{~K}$ USB (NCNR, Świerk, Poland).

This set-up was transferred to the Polkowice-Sieroszowice P1 salt cavern at the beginning of July 2014, together with the commercial portable spectrometer described below. The one-day (exactly $24 \mathrm{~h}$ ) background spectrum of unshielded spectrometer was collected. The background of the same spectrometer at the ground level was previously characterized during the 48-day long measurement and therefore it was already well known.

\section{Portable in situ system}

The GR4020 spectrometer (Canberra Industries, Inc., USA) consists of a reverse-electrode type high-purity germanium (REGe) detector with a crystal of $40 \%$ efficiency, $61 \mathrm{~mm}$ in diameter and $63 \mathrm{~mm}$ in length, a portable spectroscopy workstation InSpector $^{\mathrm{TM}} 2000$ (8194 channels) based on a digital signal processing (DSP ${ }^{\mathrm{TM}}$ ) technology and a portable personal computer (PC). The detector as operating in the temperature of liquid nitrogen $\left(\mathrm{LN}_{2}\right)$ is characterized by the resolution of $2.08 \mathrm{keV}$ and the Peak-to-Compton (P/ C) ratio of $57 / 1$ at $1.33 \mathrm{MeV}{ }^{60} \mathrm{Co}$ line. The applied spectrometric gain 5.0 together with the carbon composite entrance window (0.6 mm thick) makes possible to register gamma-rays in the energy range of $6 \mathrm{keV}-3.2 \mathrm{MeV}$. The registration and analysis of the spectra were performed with the use of Genie ${ }^{\mathrm{TM}} 2000$ v.3.2.1 software package. The efficiency calibration has been done for the geometry of a room/box with internal surface contamination using In situ Counting mathematical Software (ISOCS ${ }^{\mathrm{TM}}$ ). This tool utilizes the full factory characterization of a specific detector done by the manufacturer with the use of NISTtraceable sources and MCNP Monte Carlo modelling code. The dimensions of the room as well as the detector set-up corresponded to the experimental conditions. However, the distribution of radioactivity was very simplified, assuming only surface contamination instead of a real volumetric board of radionuclides. For energetic calibration the following solid sealed sources $(1 \mathrm{~cm}$ in diameter, activity $\sim 40 \mathrm{kBq}$ ), placed $10 \mathrm{~cm}$ from the detector front 
surface, were used: ${ }^{22} \mathrm{Na},{ }^{54} \mathrm{Mn},{ }^{57} \mathrm{Co},{ }^{60} \mathrm{Co},{ }^{65} \mathrm{Zn},{ }^{109} \mathrm{Cd}$, ${ }^{133} \mathrm{Ba}$ and ${ }^{137} \mathrm{Cs}$.

The detector was located approximately in the centre of the cavern, directly on the salt surface. Therefore, the germanium crystal was approximately $10 \mathrm{~cm}$ above the level of the cavern's floor and directed parallel to it, i.e. facing the far end of the cavern. The spectrum was registered twice. The first spectrum was acquired for $21 \mathrm{~h}$ with a detector surrounded by a circular, $2.5 \mathrm{~cm}$ thick, lead shielding. The second spectrum $(23 \mathrm{~h})$ was taken using the same set-up, but with the unshielded detector.

\section{Results and discussion}

The obtained spectra of gamma radiation registered in the centre of the salt cavern using the portable REGe detector with $2.5 \mathrm{~cm}$-thick lead shielding and without it as well as for the unshielded low-background spectrometer are presented in Figs. 1 and 2, respectively. The spectra clearly demonstrate that the studied location has surprisingly low potassium content. The other important property of this location is the lack of annihilation peak on the spectrum of low-background spectrometer. This part of the gamma-ray spectrum is usually assigned to the cosmic component $[7$, 8] in underground laboratories. Moreover, the spectrum of unshielded low-background spectrometer (Fig. 2) is dominated by the decay products of ${ }^{222} \mathrm{Rn}$. The lack of $186 \mathrm{keV}$ ${ }^{226} \mathrm{Ra}$ photopeak indicates that it is airborne radon, transported with the ventilation ducts, and not originating onsite from ${ }^{226} \mathrm{Ra}$ incorporated in the salt.

The detailed identification of photopeaks and the results of their quantitative analysis, together with the values of the statistical uncertainties $(k=1)$, for both detectors are given in Table 1.

The comparison of the data presented in Table 1 shows that for the nuclides of thorium and actinium series the count rates of the shielded and unshielded portable detector are close to each other, especially at low energies, i.e. the shielding does not reduce substantially photons coming from actinium and thorium series, although the observed decrease is beyond the uncertainty level. This confirms that the detector at low energies mainly counts photons which are produced within the cryostat or germanium crystal itself, i.e. caused by radioactive impurities of the detector. Moreover, the uranium/actinium/thorium ratio seen by a standard high-purity germanium (REGe) portable spectrometer is equal to $0.619(13) / 0.016(2) / 0.022$ (2) for the unshielded detector and $0.133(6) / 0.019$ (1)/0.016 (1) with the shielding applied.

In the case of the uranium series one can also notice that the count rates ratio between the shielded and unshielded portable detector is changing with energy, but for low energies the values are still higher than they should be in the case of the absence of internal detector impurities. This demonstrates that the uranium series nuclides are inside the detector. The count rate within the potassium ${ }^{40} \mathrm{~K}$ line matches the efficiency of the lead shielding used, which
Fig. 1 In situ gamma-ray spectra registered in the $\mathrm{P} 1$ cavern by the portable spectrometer (REGe) with $2.5 \mathrm{~cm}$ lead shielding (solid line) and without shield (dotted line). The inset shows a zoom of the low-energy part of these spectra up to $360 \mathrm{keV}$. The scaling factor of vertical axes corresponds to the ratio of ${ }^{40} \mathrm{~K}$ peak counts $($ i.e. $\sim \times 5$ ) for unshielded versus shielded detector

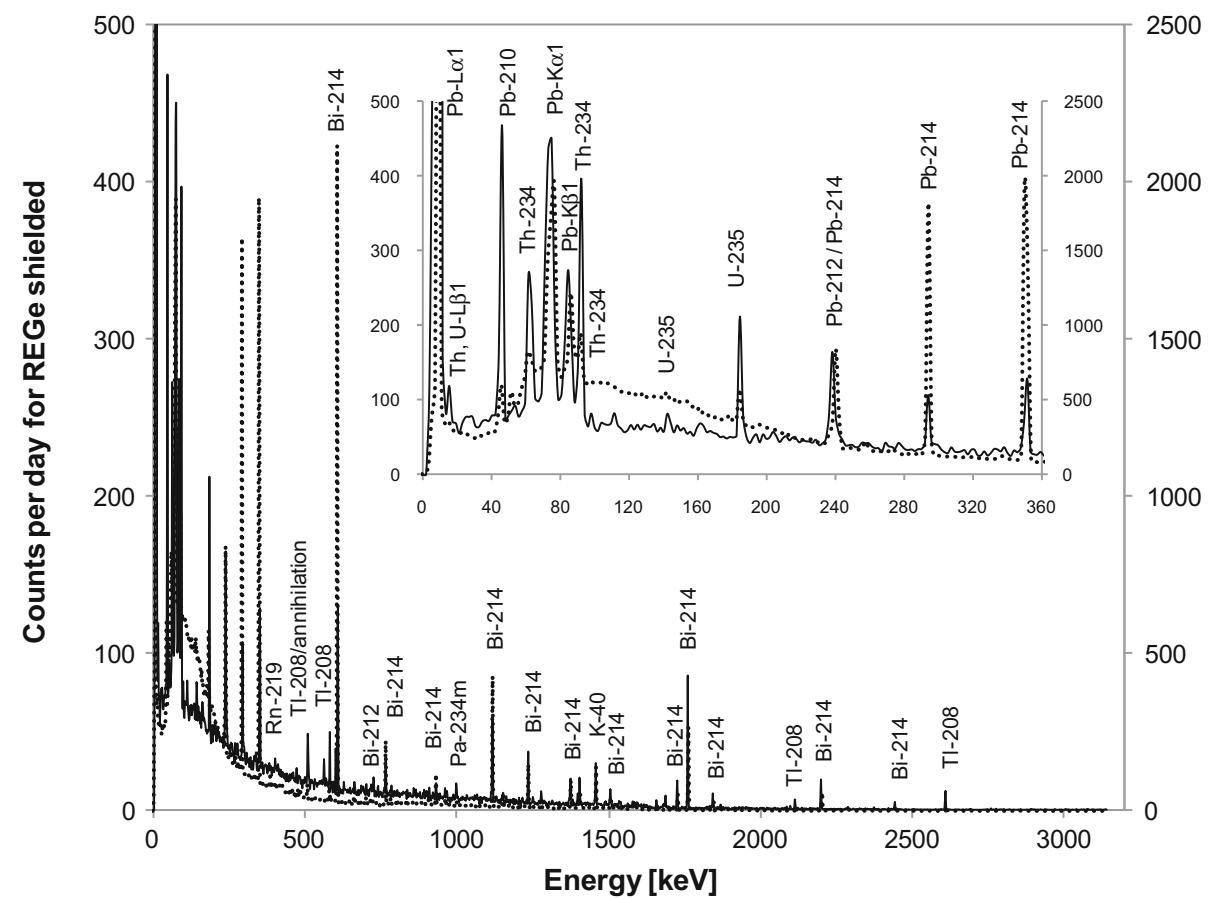


Fig. 2 In situ gamma-ray spectrum registered for $24 \mathrm{~h}$ in the P1 cavern by the lowbackground HPGe spectrometer without shielding. The inset shows a zoom of the low-energy part of the spectrum up to $360 \mathrm{keV}$

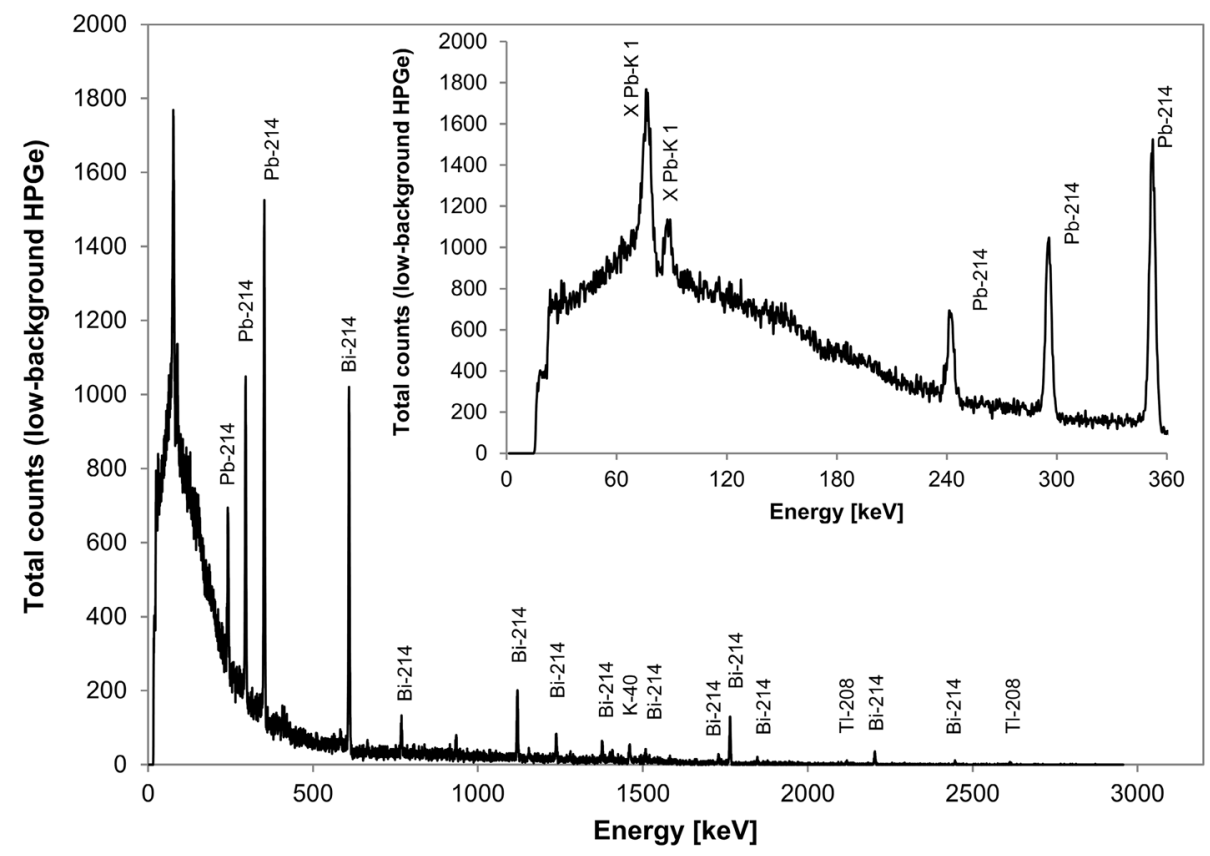

suggests that the measured potassium is the component of the salt rather than constituting the internal detector impurity in this case.

The ratio between the count rates for the gamma lines of uranium member series for both unshielded detectors used can be described by an exponential curve with constant fraction (Fig. 3). For higher energies it becomes constant and equal to 0.35 . In the case of an absence of internal impurities in the portable detector, the ratio plot in Fig. 3 should be $\approx 1$ regardless the energy, since the counting efficiency for both detectors used are close to each other. The ratio $<1$ indicates that more radioimpurities is present in the portable detector than in a low-background one, what was also concluded before on the basis of data presented in Table 1. We have found that also for ${ }^{40} \mathrm{~K}$ this ratio is about 0.34 . However, for thorium series, namely from ${ }^{208} \mathrm{Tl}$ at $2615 \mathrm{keV}$, it is equal to 0.22 . This in turn confirms that the majority of gamma photons from the decay of thorium series originates from the portable detector impurities, and therefore for a low background system we can expect lower values.

The comparison of the gamma-ray flux in several underground laboratories, presented in Table 2, demonstrates that the investigated location exhibits an extremely low level of natural radiation, both measured with the lowbackground spectrometer and registered by the portable detector. In this table, for comparison purpose, our earlier result [6] is also shown, obtained with the use of detector with different housing, i.e. not equipped with the carbon composite window.

On the base of the photo-peak count rates registered by the REGe detector and by applying the efficiency determined by ISOCS $^{\mathrm{TM}}$, the gamma-ray flux has been determined as 0.124 (2) photons per $\mathrm{cm}^{2}$ per second. However, this value seems to be overestimated since the efficiency obtained using mathematical calibration software $\left(\right.$ ISOCS $^{\mathrm{TM}}$ ) is probably underestimated, i.e. achieved from the model of radioactivity distribution on the cavern surface instead of being uniformly distributed within the volume of the salt deposit. The main radon daughters: ${ }^{210} \mathrm{~Pb},{ }^{214} \mathrm{~Pb}$ and ${ }^{214} \mathrm{Bi}$, are responsible for $0.026(1) \mathrm{cm}^{-2} \mathrm{~s}^{-1}$ photon flux, whereas the internal impurities of portable spectrometer setup (inherent detector and shielding radioimpurities) have the main impact on the registered gamma radiation with this system of about $67 \%$. If the radioactive impurities connected with experimental setup were suppressed (the case of low-background spectrometer), the main background contribution would be connected with radon decay products, whereas potassium ${ }^{40} \mathrm{~K}$ salt-content contribution would be about $3 \%$.

The total spectrum continuum photon flux reaches 0.18 (5) $\mathrm{cm}^{-2} \mathrm{~s}^{-1}$. This value is a superposition of photons emitted by radionuclides, scattered inside the detector volume and electromagnetic avalanche connected with cosmic radiation and its secondaries. Therefore it should not be directly referenced to the contribution of muon-related events.

The comparison with the spectrum registered on the earth's surface by the low-background detector (shown in Fig. 4), placed within the housing of lead $10 \mathrm{~cm}$ thick, has been performed. One can notice that for energies below $600 \mathrm{keV}$ the $d=10 \mathrm{~cm}$ lead shield reduces external gamma-rays to a negligible level, namely the attenuation factor $\exp (\mu \mathrm{d})$, based on linear attenuation coefficient $\mu$, is 
Table 1 Naturally occurring radionuclides registered in the P1 cavern with the spectrometric systems used: unshielded low-background HPGe and unshielded as well as shielded $(2.5 \mathrm{~cm} \mathrm{~Pb})$ portable HPGe

\begin{tabular}{|c|c|c|c|c|c|}
\hline \multirow[t]{3}{*}{ Decay chain } & \multirow[t]{3}{*}{ Isotope } & \multirow[t]{3}{*}{ Energy $(\mathrm{keV})$} & \multicolumn{3}{|c|}{ Count rate $\left(\mathrm{s}^{-1}\right)$} \\
\hline & & & \multicolumn{2}{|c|}{ Portable HPGe } & \multirow{2}{*}{$\begin{array}{l}\text { Low-background } \\
\text { HPGe }\end{array}$} \\
\hline & & & Unshielded & With $2.5 \mathrm{~cm} \mathrm{~Pb}$ shield & \\
\hline- & $\mathrm{X} \mathrm{Pb}$ & 10.55 & $0.3126(23)$ & $0.5029(26)$ & - \\
\hline Uranium & ${ }^{210} \mathrm{~Pb}$ & 46.54 & $0.0219(12)$ & $0.0270(8)$ & $<0.02$ \\
\hline Uranium & ${ }^{234} \mathrm{Th}$ & 63.29 & $0.0159(17)$ & $0.0160(9)$ & $<0.0063$ \\
\hline Uranium & ${ }^{234} \mathrm{~Pa}$ & 73.92 & - & $0.0153(6)$ & $<0.0074$ \\
\hline- & $\mathrm{X} \mathrm{Pb}$ & 74.97 & $0.0611(12)$ & $0.0304(7)$ & $<0.0074$ \\
\hline- & $\mathrm{X} \mathrm{Bi}$ & 77.12 & $0.1041(14)$ & $0.0073(5)$ & $<0.0072$ \\
\hline- & $\mathrm{X} \mathrm{Pb}$ & 84.94 & - & $0.0142(5)$ & $0.0185(18)$ \\
\hline- & $\mathrm{X} \mathrm{Bi}$ & 87.34 & $0.0343(10)$ & $0.0057(4)$ & $<0.0063$ \\
\hline Uranium & ${ }^{234} \mathrm{Th}$ & 92.59 & $0.0238(10)$ & $0.0192(10)$ & $<0.0058$ \\
\hline Actinium + Uranium & ${ }^{235} \mathrm{U}+{ }^{226} \mathrm{Ra}$ & $185.71+186.21$ & $0.0158(15)$ & $0.0108(6)$ & $<0.0043$ \\
\hline Thorium & ${ }^{212} \mathrm{~Pb}$ & 238.63 & $0.0121(6)$ & $0.0092(4)$ & $<0.0043$ \\
\hline Actinium & ${ }^{219} \mathrm{Rn}$ & 271.23 & - & $0.0044(2)$ & $<0.0039$ \\
\hline Uranium & ${ }^{214} \mathrm{~Pb}$ & 295.21 & $0.1082(14)$ & $0.0043(6)$ & $0.0577(12)$ \\
\hline Uranium & ${ }^{214} \mathrm{~Pb}$ & 351.92 & $0.1820(17)$ & $0.0075(6)$ & $0.0957(13)$ \\
\hline Actinium & ${ }^{219} \mathrm{Rn}$ & 401.81 & - & $0.0039(2)$ & $<0.0021$ \\
\hline Thorium & ${ }^{208} \mathrm{Tl}$ & 510.77 & $0.0038(6)$ & 0.0028 & $<0.0016$ \\
\hline Thorium & ${ }^{208} \mathrm{Tl}$ & 583.19 & $0.0033(4)$ & $0.0021(3)$ & $0.0017(6)$ \\
\hline Uranium & ${ }^{214} \mathrm{Bi}$ & 609.31 & $0.1549(14)$ & 0.0125 & $0.0687(10)$ \\
\hline Uranium & ${ }^{214} \mathrm{Bi}$ & 665.45 & $0.0042(5)$ & $0.0002(2)$ & $0.0014(3)$ \\
\hline Thorium & ${ }^{212} \mathrm{Bi}$ & 727.33 & $0.0012(2)$ & $0.0005(2)$ & $<0.0012$ \\
\hline Uranium & ${ }^{214} \mathrm{Bi}$ & 768.36 & $0.0142(6)$ & 0.0023 & 0.0059 (4) \\
\hline Uranium & ${ }^{214} \mathrm{Bi}$ & 964.77 & $0.0013(2)$ & $0.0003(2)$ & $<0.00096$ \\
\hline Uranium & ${ }^{234 \mathrm{~m}} \mathrm{~Pa}$ & 1001.03 & $0.0014(4)$ & $0.0008(2)$ & $<0.0010$ \\
\hline Uranium & ${ }^{214} \mathrm{Bi}$ & 1120.29 & $0.0328(7)$ & $0.0055(4)$ & $0.0129(5)$ \\
\hline Uranium & ${ }^{214} \mathrm{Bi}$ & 1238.11 & $0.0121(5)$ & $0.0024(2)$ & $0.0045(3)$ \\
\hline- & ${ }^{40} \mathrm{~K}$ & 1460.83 & $0.0107(4)$ & $0.0023(2)$ & $0.0036(3)$ \\
\hline Uranium & ${ }^{214} \mathrm{Bi}$ & 1764.50 & $0.0246(6)$ & 0.0068 & $0.0090(4)$ \\
\hline Uranium & ${ }^{214} \mathrm{Bi}$ & 2204.21 & $0.0060(3)$ & $0.0017(2)$ & $0.0024(2)$ \\
\hline Thorium & ${ }^{208} \mathrm{Tl}$ & 2614.53 & $0.0015(1)$ & 0.0012 & $0.00033(6)$ \\
\hline
\end{tabular}

Only the lines registered at least on two spectra are presented

higher than $10^{6}$ [12]. Thus, from the low energy part of the spectrum it is possible to estimate the effective count rates from the internal (detector and shield) content of radionuclides and then correct the high energy part, finally calculating the expected effective count rate. The constructed low-background HPGe spectrometer is ultimately planned to operate in the salt layer in configuration with a $10 \mathrm{~cm}$ lead housing. In the P1 cavern in the simplified approach one can measure the count rates for different lines in the unshielded spectrometer and scale them by attenuation coefficients for $10 \mathrm{~cm}$ lead, which for example results in scaling factors of $7.44 \times 10^{-7}$ for $609 \mathrm{keV}$ line and of 0.0077 for $2614 \mathrm{keV}$ line. The spectra registered with the shielded and unshielded portable system (Fig. 1) can be used to demonstrate that such an approach is misleading, which is due to the non-scaling component of the intrinsic impurities. However, the results obtained with the portable detector can be used to estimate the effective reducing power for the shield made of standard lead in the case of ${ }^{40} \mathrm{~K}$ and ${ }^{208} \mathrm{Tl}$, after taking into consideration the correction to standard portable detector radioactive impurities. Such an assessment could be then applied to estimate the reducing power of the planned $10 \mathrm{~cm}$ thick lead shield. For example, the reduction factor of the gamma-ray flux for a fourfold increase of lead thickness (from 2.5 to $10 \mathrm{~cm}$ ) is equal to $\mathrm{e}^{4} \approx 55$. However, such a simple approach cannot be applied since the low-background detector has its own radioactive non-scalable impurities. In 
Fig. 3 The ratio between the count rates of the unshielded low background (HPGe) detector and portable (REGe) detector for main gamma lines $\left(\mathrm{cps}_{\mathrm{HPGe}} / \mathrm{cps}_{\mathrm{REGe}}\right)=\mathrm{f}(\mathrm{E})$ from uranium series members $\left({ }^{214} \mathrm{~Pb}\right.$ and $\left.{ }^{214} \mathrm{Bi}\right)$. The count rates were measured in the P1 salt cavern

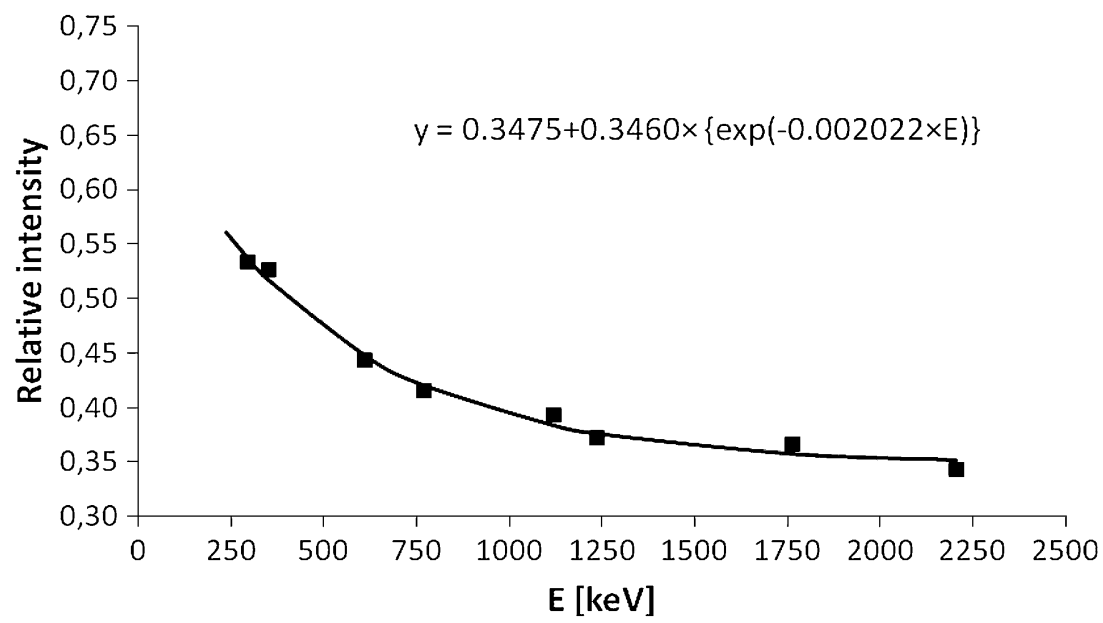

Table 2 The comparison of the integral count rates in the energy range of 7-2734 keV in several European underground experimental sites, as seen by the HPGe detectors

\begin{tabular}{|c|c|c|c|c|c|c|}
\hline \multirow[t]{2}{*}{ Location } & \multirow[t]{2}{*}{ Boulby } & \multirow[t]{2}{*}{ Gran Sasso } & \multirow[t]{2}{*}{ Modane } & \multicolumn{3}{|l|}{ Sieroszowice } \\
\hline & & & & $\begin{array}{l}\text { Portable REGe } \\
\text { spectrometer }\end{array}$ & $\begin{array}{l}\text { Low-background } \\
\text { HPGe spectrometer }\end{array}$ & $\begin{array}{l}\text { Portable HPGe } \\
\text { spectrometer }\end{array}$ \\
\hline Count rate $\left(\mathrm{s}^{-1}\right)$ & $\begin{array}{l}\text { 6.5-28 (several } \\
\text { locations) }\end{array}$ & $\begin{array}{c}\text { 8-60 (several } \\
\text { locations) }\end{array}$ & $\begin{array}{l}\text { 15-108 (several } \\
\text { locations) }\end{array}$ & $5.79(1)$ & $3.92(1)$ & $1.95(2)^{\mathrm{a}}$ \\
\hline Source & [9] & [10] & [11] & This study & This study & [6] \\
\hline Detector type & HPGe, p-type & HPGe, p-type & HPGe, p-type & HPGe, n-type & HPGe, n-type & HPGe, p-type \\
\hline Relative efficiency (\%) & 32 & 32 & 32 & 40 & 25 & 30 \\
\hline
\end{tabular}

${ }^{a}$ Different measuring range (40-2700 keV) and detector endcap (without carbon-composite entrance window)

Fig. 4 Gamma-ray spectrum registered for 48 days at the ground level in the IFJ PAN by the low-background HPGe spectrometer with $10 \mathrm{~cm}$ lead shielding. The aim of this measurement, beside the background study, was to increase neutron effects, thus the shield included also water moderator $(50 \mathrm{~L})$ placed around the detector and $2 \mathrm{~mm}$ thick cadmium plate placed from its top. The inset in the graph shows a zoom of the low-energy part of the spectrum up to $400 \mathrm{keV}$

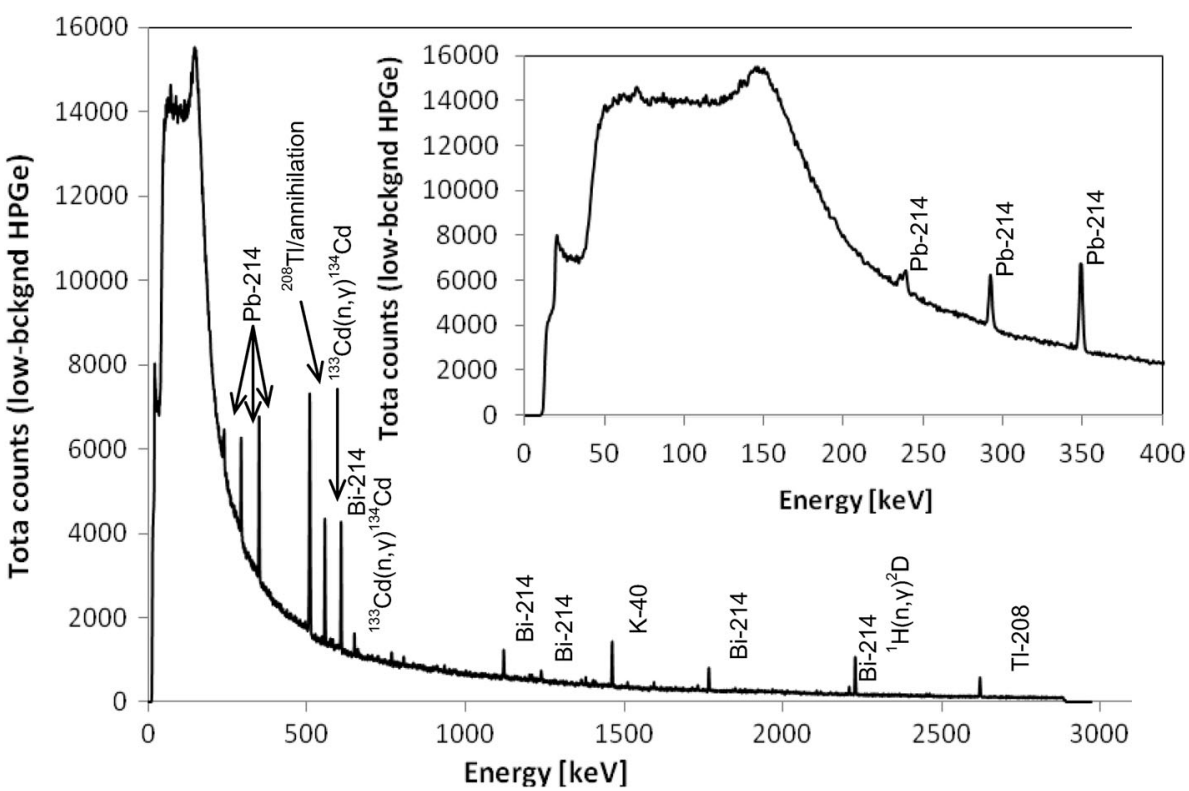


Table 3 Count rates $\left(\mathrm{s}^{-1}\right)$ for the main lines for low-background gamma-rays spectrometer: shielded by $10 \mathrm{~cm}$ of lead, obtained in 48-day measurements on the ground level; unshielded, measured underground in the P1 salt cavern; expected for the shielded by $10 \mathrm{~cm}$ of lead in P1 salt cavern

\begin{tabular}{|c|c|c|c|c|c|}
\hline \multirow[t]{2}{*}{ Energy (keV) } & \multirow[t]{2}{*}{ Origin $[3,4]$} & \multicolumn{2}{|c|}{ Ground level, shielded } & \multirow{2}{*}{$\begin{array}{l}\text { Unshielded, P1 cavern } \\
\text { (the same as in Table 1) }\end{array}$} & \multirow{2}{*}{$\begin{array}{l}\text { Prediction for shielded } \\
\text { in P1 cavern }{ }^{\text {a }}\end{array}$} \\
\hline & & $\left(\mathrm{s}^{-1}\right)$ & Relative uncertainty & & \\
\hline 242.0 & ${ }^{214} \mathrm{~Pb}$ & 0.001248 & 0.075 & & 0.0012 \\
\hline 295.2 & ${ }^{214} \mathrm{~Pb}$ & 0.002114 & 0.039 & 0.0587 & 0.0021 \\
\hline 351.1 & ${ }^{214} \mathrm{~Pb}$ & 0.003709 & 0.020 & 0.0957 & 0.0037 \\
\hline 510.8 & $\mathrm{e}^{+} \mathrm{e}^{-}$ & 0.007602 & 0.0098 & & $<0.0001$ \\
\hline 609.3 & ${ }^{214} \mathrm{Bi}$ & 0.002902 & 0.018 & 0.0687 & 0.0029 \\
\hline 768.4 & ${ }^{214} \mathrm{Bi}$ & 0.000288 & 0.12 & 0.0059 & 0.00027 \\
\hline 911.2 & ${ }^{228} \mathrm{Ac}$ & 0.000142 & 0.27 & & 0.00013 \\
\hline 1120.3 & ${ }^{214} \mathrm{Bi}$ & 0.000682 & 0.051 & 0.0129 & 0.00060 \\
\hline 1238.1 & ${ }^{214} \mathrm{Bi}$ & 0.000293 & 0.11 & 0.045 & 0.00022 \\
\hline 1460.8 & ${ }^{40} \mathrm{~K}$ & 0.001222 & 0.026 & 0.0036 & 0.0012 \\
\hline 1764.5 & ${ }^{214} \mathrm{Bi}$ & 0.000572 & 0.043 & 0.0090 & 0.00036 \\
\hline 2614.3 & ${ }^{208} \mathrm{Tl}$ & 0.000625 & 0.033 & 0.00033 & 0.00010 \\
\hline
\end{tabular}

${ }^{a}$ See text for details

the case of the estimation of the dominating gamma emitter- ${ }^{222} \mathrm{Rn}$ decay products, we took under consideration that radon levels are similar on the ground level $[5,13$, $14]$ and in the P1 cavern and equal to $15.4 \pm 1.1 \mathrm{~Bq} / \mathrm{m}^{3}$, as measurements done in 30-hour cycle have shown. For energies below $700 \mathrm{keV}$ (namely: 295, 352, $609 \mathrm{keV}$ ) we assumed that the count rates (as governed by the radioactive impurities within the cryostat, detector and in-shield radon daughters levels) on the ground level and in the P1 cavern would be the same. As mentioned above, the $10 \mathrm{~cm}$ lead shield is thick enough to eliminate any outer sources for low energy gammas, i.e. the spectrometer background is caused only by radioactivity within the shielded volume. Then we calculated the excess of count rates for 768, 1120, 1238 and $1764 \mathrm{keV}$ lines for the ground level laboratory, taking into account the count rates from low energy peaks and using a calibration curve for cylindrical geometry. In our prediction, the intensities of radon-daughters lines are taken from the ground level background measurement for the shielded detector reduced by this factor. A similar reduction of "excess" was used for the calculations of the predicted count rate for ${ }^{208} \mathrm{Tl}$ in $2614 \mathrm{keV}$ line on the basis of $911 \mathrm{keV}$ line of ${ }^{228} \mathrm{Ac}$. For potassium we assumed conservatively the same count rate underground as for the ground level. The results are presented in Table 3.

\section{Conclusions}

Measurements performed with the use of shielded and unshielded configuration of two gamma spectrometry systems clearly demonstrated that there is a difference in the gamma-ray count rates coming from particular radioactive decay series and registered by semiconductor spectrometers placed in the middle of the underground salt cavern. The use of two spectrometers (commercial and low-background) with comparable dimensions and crystal housings allowed to confirm that thorium and actinium series isotopes can be effectively suppressed by careful choosing of a detector material.

The comparison of the spectra registered by the commercially available portable REGe detector and the specially constructed low-background HPGe spectrometer demonstrates that internal radioactive impurities within the measurement device in the environment with a very lowlevel of natural radioactivity are the main sources of the background signal influencing the registered spectra. Under some approximate assumption the prediction of the efficiency of a lead shielding (of the thickness being in agreement with the numerical findings [15]) was made. According to these calculations, with the studied lowbackground spectrometer in the shielded $(10 \mathrm{~cm} \mathrm{~Pb})$ configuration the background reduction of about $30 \%$ could be achieved.

Moreover, the influence of the reduction of internal radioimpurities/background gamma-radiation signal, achieved by the construction of low-background detector in comparison with standard portable systems, can be roughly assessed from the ratio $\left(\mathrm{cps}_{\mathrm{HPGe}} / \mathrm{cps}_{\mathrm{REGe}}\right)=\mathrm{f}(\mathrm{E})$ developed on the base of uranium series and expand to other nuclides in high-energy region, to test their internal-detector or external-environmental origin.

It has been shown (Table 2) that the obtained results are dependent from the type of germanium crystal, i.e. the 
n-type spectrometer register lower count rates than p-type systems. Therefore, they could not be related straightforward to each other, although other features of the detectors are comparable.

Unlike the underground laboratories located in different geological formations (e.g. [16]), the radon concentration in the salt chamber of copper mine in Poland is comparable to the ground level concentration, being of the order of 15 (1) $\mathrm{Bq} / \mathrm{m}^{3}$. This confirms that the main source of radon and its products is the ventilation air and not the radium incorporated in the salt rock. The obtained result of radon concentration is in agreement with literature reported investigations for salt mine locations, e.g. INR Solotvina laboratory [3], Khewra Salt Mines [14].

Among the advantages of studied location in deep underground salt mine $(2200 \mathrm{~m}$ w.e.) low levels of radon concentration and ${ }^{40} \mathrm{~K}$ count rate $\left(0.004 \mathrm{~s}^{-1} \mathrm{~kg}^{-1}\right)$ as well as the undetectable level of cosmic muon component (annihilation peak) on the spectrum of low-background spectrometer should be stressed. Therefore, these findings support the salt layer of the Polkowice-Sieroszowice mine as the location of a low-background underground laboratory-the SUNLAB (Sieroszowice UNderground LABoratory) project.

Acknowledgments We wish to thank the Polkowice-Sieroszowice mine management and engineers for their help during measurements. This work was supported by the National Centre for Research and Development, Poland (ERA-NET-ASPERA/03/2011), including the design and construction of the low-background HPGe spectrometer. M.H. acknowledges support from the National Science Centre, Poland, project Preludium DEC-2011/03/N/ST/01971.

Open Access This article is distributed under the terms of the Creative Commons Attribution 4.0 International License (http://crea tivecommons.org/licenses/by/4.0/), which permits unrestricted use, distribution, and reproduction in any medium, provided you give appropriate credit to the original author(s) and the source, provide a link to the Creative Commons license, and indicate if changes were made.

\section{References}

1. Bellini G, (Borexino Collaboration) et al (2012) Cosmic-muon flux and annual modulation in Borexino at $3800 \mathrm{~m}$ waterequivalent depth. J Cosmol Astropart Phys 05(015):1-13

2. Kalousis LN, Guarnaccia E, Link JM, Mariani C, Pelkey R (2014) Cosmic muon flux measurements at the Kimballton Underground Research Facility. J Instrum 9:P08010
3. Povinec PP, Betti M, Jull AJT, Vojtyla P (2008) New isotope technologies in environmental physics. Acta Physica Slovaca 58(1):1-154

4. Laubenstein M, Hult M, Gasparro J, Arnold D, Neumaier S, Heusser G, Kohler M, Povinec P, Reyss J-L, Schwaiger M, Theodorsson P (2004) Underground measurements of radioactivity. Appl Radiat Isot 61(2-3):167-172

5. Zalewska A, Pytel W, Chorowski M, Cygan S, Hanzel S, Januszewska K, Jaroń L, Kisiel J, Lankof L, Markiewicz A, Markowski P, Martuszka P, Raczyński M, Sadecki Z, Sobczyk J, Sulej R, Szarska M, Ślizowski J, Szeglowski T, Urbańczyk K (2010) LAGUNA in Polkowice-Sieroszowice mine in Poland. Acta Phys Pol B 41(7):1803-1812

6. Kisiel J, Budzanowski M, Dorda J, Kozak K, Mazur J, Mietelski JW, Puchalska M, Tomankiewicz E, Zalewska A (2010) Measurements of natural radioactivity in the salt cavern of the Polkowice-Sieroszowice copper mine. Acta Phys Pol B 41(7): 1813-1819

7. Buchmüller W, Garny M (2012) Decaying vs. annihilating dark matter in light of a tentative gamma-ray line. J Cosmol Astropart Phys 08:035

8. Banjanac R, Maletic D, Jokovic D, Veselinovic N, Dragic A, Udovicic V, Anicin I (2014) On the omnipresent background gamma radiation of the continuous spectrum. Nucl Instrum Methods Phys Res Sect A 745:7-11

9. Malczewski D, Kisiel J, Dorda J (2013) Gamma background measurements in the Boulby Underground Laboratory. J Radioanal Nucl Chem 298:1483-1489

10. Malczewski D, Kisiel J, Dorda J (2013) Gamma background measurements in the Gran Sasso National Laboratory. J Radioanal Nucl Chem 295:749-754

11. Malczewski D, Kisiel J, Dorda J (2012) Gamma background measurements in the Laboratoire Souterrain de Modane. J Radioanal Nucl Chem 292:751-756

12. Hubbel JH, Seltzer SM (1995) Tables of X-ray mass attenuation coefficients and mass energy-absorption coefficients from $1 \mathrm{keV}$ to $20 \mathrm{MeV}$ for elements $\mathrm{Z}=1$ to 92 and 48 additional substances of dosimetric interest. National Institute of Standard and Technology, NISTIR 5632 (http://www.nist.gov/pml/data/xraycoef/ index.cfm)

13. Wysocka M (2010) Investigations of outbursts and tremors in Polish collieries with application of radon measurements. Nukleonika 55(4):495-499

14. Baloch MA, Qureshi AA, Waheed A, Ali M, Ali N, Tufail M, Batool S, Akram M, Iftikhar P, Qayyum H, Manzoor S, Khan HA (2012) A study on natural radioactivity in Khewra Salt Mines, Pakistan. J Radiat Res 53:411-421

15. Vojtyla P, Povinec PP (2000) A Monte Carlo simulation of background characteristics of low-level HPGe detectors. Appl Radiat Isot 53(1-2):185-190

16. Kohler M, Degering D, Laubenstein M, Quirin P, Lampert M-O, Hult M, Arnold D, Neumaier S, Reyss J-L (2009) A new lowlevel $\gamma$-ray spectrometry system for environmental radioactivity at the underground laboratory Felsenkeller. Appl Radiat Isot 67:736-740 